\title{
The Influence of Plastic Deformation and Cooling Rates on the Microstructural Constituents of an Ultra-low Carbon Bainitic Steel
}

\author{
J. R. YANG, C. Y. HUANG and C. S. CHIOU ${ }^{11}$
}

Institute of Materials Science and Engineering, National Taiwan University, 1 Roosevelt Rd. Sec. 4, Taipei, Taiwan, Republic of China. 1) Department of Mechanical Engineering, Yuan-Ze Institute of Technology, 135 Far-East Rd., Chung-Li, Taiwan, Republic of China.

(Received on March 3, 1995; accepted in final form on May 26, 1995)

\begin{abstract}
An experimental ultra-low carbon bainitic steel was prepared to investigate the effect of a prior compressive deformation on the morphology of the transformation product during continuous cooling. It is found that at the higher cooling rate the deformed austenite tends to form the non-parallel plates of acicular ferrite, and that at the lower cooling rate the deformed austenite tends to form the parallel plates of bainitic ferrite. The orientation relationships between adjacent grains of acicular ferrite have been studied using the analysis of axis-angle pair. The result shows that the adjacent variants have nearly the same orientation in space, which is analogous to the case in alloy-steel weld metals. Furthermore, based on a thermodynamic analysis, it is indicated that acicular ferrite transformation (from deformed austenite) also exhibits the phenomenon of incomplete reaction, where the reaction ceases well before the residual austenite achieves its equilibrium carbon concentration.
\end{abstract}

KEY WORDS: deformed austenite; bainite; acicular ferrite; continuous cooling; axis-angle pair; isothermal transformation; incomplete reaction.

\section{Introduction}

The development of the so-called ultra-low carbon bainitic (ULCB) steels originated from the concept that the interplate carbides in conventional bainitic ferrite can be eliminated completely as the carbon content of the steels is extremely low. ${ }^{1-4)}$ These kinds of steels have been found to possess excellent combinations of good toughness, strength and weldability, and have been designed for use in high strength line pipes in Arctic or submarine environments. The production of these steels is usually under a controlled-rolling and acceleratedcooling process. Hence, the accumulated strain in the deformed austenite should have impact on the bainitic transformation. The purpose of this work was to investigate the effect of prior compressive deformation of austenite (followed by continuous cooling transformations) on microstructural constituents in an ULCB steel. In addition, this work was aimed at the further exploration of aspects of the transformation mechanism as the deformed austenite of the steel was isothermally transformed in the temperature range of bainite formation.

\section{Experimental Procedures}

The experimental steel was prepared from $250 \mathrm{~kg}$ vacuum melt heats and cast into $160 \times 160 \times 250 \mathrm{~mm}^{3}$ ingot. The chemical composition of the steel studied is listed in Table 1. The details of the steel plate preparation by a controlled-rolling process have been presented elsewhere. ${ }^{5)}$ In this work, all the thermal and thermo-mechanical treatments have been carried out on a Dilatromic III RDP deformation dilatometer of Theta Industries, Inc. Before preparation for dilatometric specimens, the pieces of steel plate were homogenized at $1200^{\circ} \mathrm{C}$ for $2 \mathrm{~h}$, then quenched into water (for the purpose of dissolving all of niobium carbonitrides), and finally removed the decarburization layer. The specimens were machined in the form of $3 \mathrm{~mm}$ diameter cylindrical rods with $6 \mathrm{~mm}$ length. Two processing schemes (Processes A and $B$ ) performed in the dilatometer without and with a $40 \%$ compressive deformation are presented in Figs. 1(a) and 1(b). After reaustenitization at $1200^{\circ} \mathrm{C}$ for $3 \mathrm{~min}$, the specimens for Process A were cooled down to the ambient temperature at a variety of cooling rates ranging from 0.5 to $30^{\circ} \mathrm{C} / \mathrm{s}$; on the other hand, the specimens for Process $\mathrm{B}$ were cooled down to $800^{\circ} \mathrm{C}$ at the cooling rate $15^{\circ} \mathrm{C} / \mathrm{s}$, immediately a $40 \%$ compressive deformation was carried out at the temperatures from 800 to $780^{\circ} \mathrm{C}$ within $6 \mathrm{~s}$, and then the deformed specimens were cooled directly

Table 1. Chemical composition of the steel. (wt\%)

\begin{tabular}{cccccccccc}
\hline $\mathrm{C}$ & $\mathrm{Mn}$ & $\mathrm{Si}$ & $\mathrm{P}$ & $\mathrm{Al}$ & $\mathrm{Ti}$ & $\mathrm{Nb}$ & $\mathrm{S}^{*}$ & $\mathrm{~B}^{*}$ & $\mathrm{~N}^{*}$ \\
\hline 0.03 & 1.85 & 0.19 & 0.009 & 0.028 & 0.024 & 0.050 & 40 & 26 & 40
\end{tabular}

$\left({ }^{*} \mathrm{~S}, \mathrm{~B}, \mathrm{~N}\right.$ in ppm) 
(a)

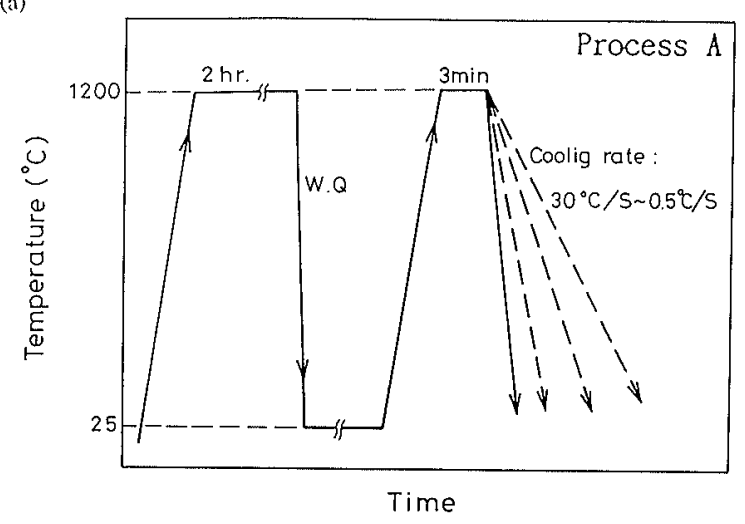

(b)

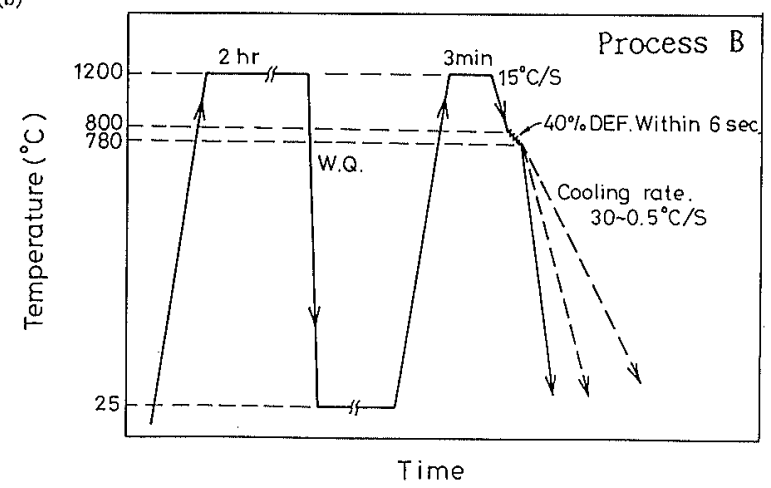

Fig. 1. Two Processing schemes (Processes A and B) performed in the dilatomeger (a) without and (b) with a $40 \%$ compressive deformation followed by continuous cooling at a variety of rates.

at the same rates as those used in process $\mathrm{A}$.

In order to investigate the effect of the prior compressive deformation on the bainite transformation behavior, two parallel experiments-Processes C and D (as shown in Fig. 2) have been performed on the dilatometer. In Process D, after austenitization at $1.200^{\circ} \mathrm{C}$ for $3 \mathrm{~min}$, the specimen was cooled down to $800^{\circ} \mathrm{C}$, given a $40 \%$ compressive deformation at $800^{\circ} \mathrm{C}$ within $2 \mathrm{~s}$, then rapidly cooled down to a temperature for isothermal transformation in the temperature range of bainite formation. Process $C$ had the same thermal treatment as Process D except that Process $C$ was without deformation at $800^{\circ} \mathrm{C}$. After isothermal transformation of bainite had been completed, the specimens were cooled to room temperature at cooling rate $120^{\circ} \mathrm{C} / \mathrm{s}$.

The corresponding microstructures obtained from Processes A, B, C and D have been examined using optical metallography, scanning electron microscopy and transmission electron microscopy.

The specimens for optical metallography were prepared from dilatometric specimens. The specimens were mechanically polished and then etched in $2 \%$ nital solution. In order to identify the particles of martensite/austenite constitutent, the specimens were observed under a PHILIPS 515 scanning electron microscope at a magnification of $1000 \times$. The volume fractions of $M / A$ constituent were measured by the point counting method. For each specimen, more than 30 frames were mea- (a)

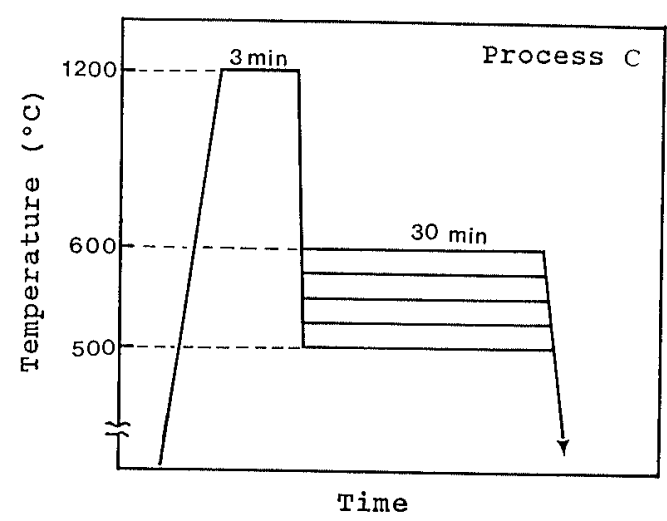

(b)

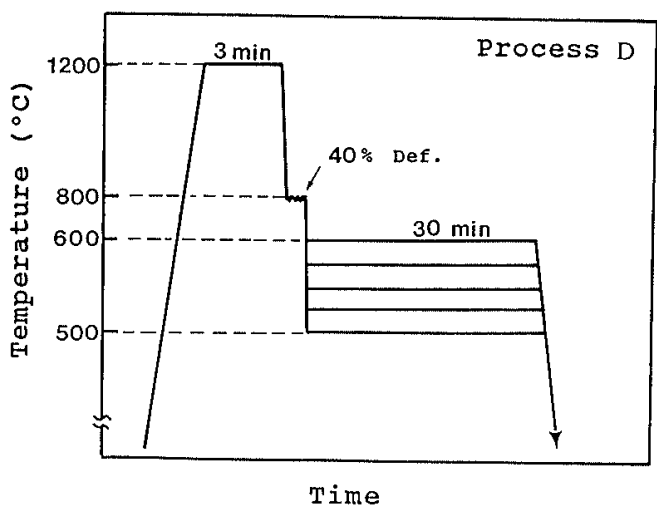

Fig. 2. Two Processing schemes (Processes $\mathbf{C}$ and D) performed in the dilatometer (a) without and (b) with a $40 \%$ compressive deformation followed by isothermal treatment for bainite and acicular ferrite formation.

sured with a grid of 400 counting points. The standard deviation of the measurement was without $0.5 \%$.

Transmission electron microscopy samples were prepared from $0.25 \mathrm{~mm}$ thick discs cut from the steel studied. For the deformed samples, the observed section was perpendicular to the direction of compression. The discs were thinned to $0.05 \mathrm{~mm}$ by abrasion on silicon carbide papers and then twin-jet electropolished using a mixture of $5 \%$ perchloric acid, 25\% glycerol and $70 \%$ ethanol at ambient temperature and $60 \mathrm{~V}$ polishing potential. They were examined using a JEOL 2000EX transmission electron microscope operating at $200 \mathrm{kV}$.

\section{Results and Discussion}

Figure 3 shows the optical microstructures obtained from the specimens treated in Process A over a wide range of final cooling rates. As the cooling rate is higher than $1{ }^{\circ} \mathrm{C} / \mathrm{s}$, high volume fraction of sheaf-like bainite with a few amounts of M/A (martensite/austenite) constituent can be obtained (Figs. 3(a)-3(d)). Furthermore, at the higher cooling rate the sub-unit platelets of bainitic ferrite become finer, and the particles of M/A constituent become thinner and more uniformly distributed in the bainitic ferrite matrix (Fig. 3(a)). As the cooling rate is lowered to $1^{\circ} \mathrm{C} / \mathrm{s}$, the microstructure (Fig. 3(e)) consists chiefly of bainitic ferrite matrix with some amounts of 


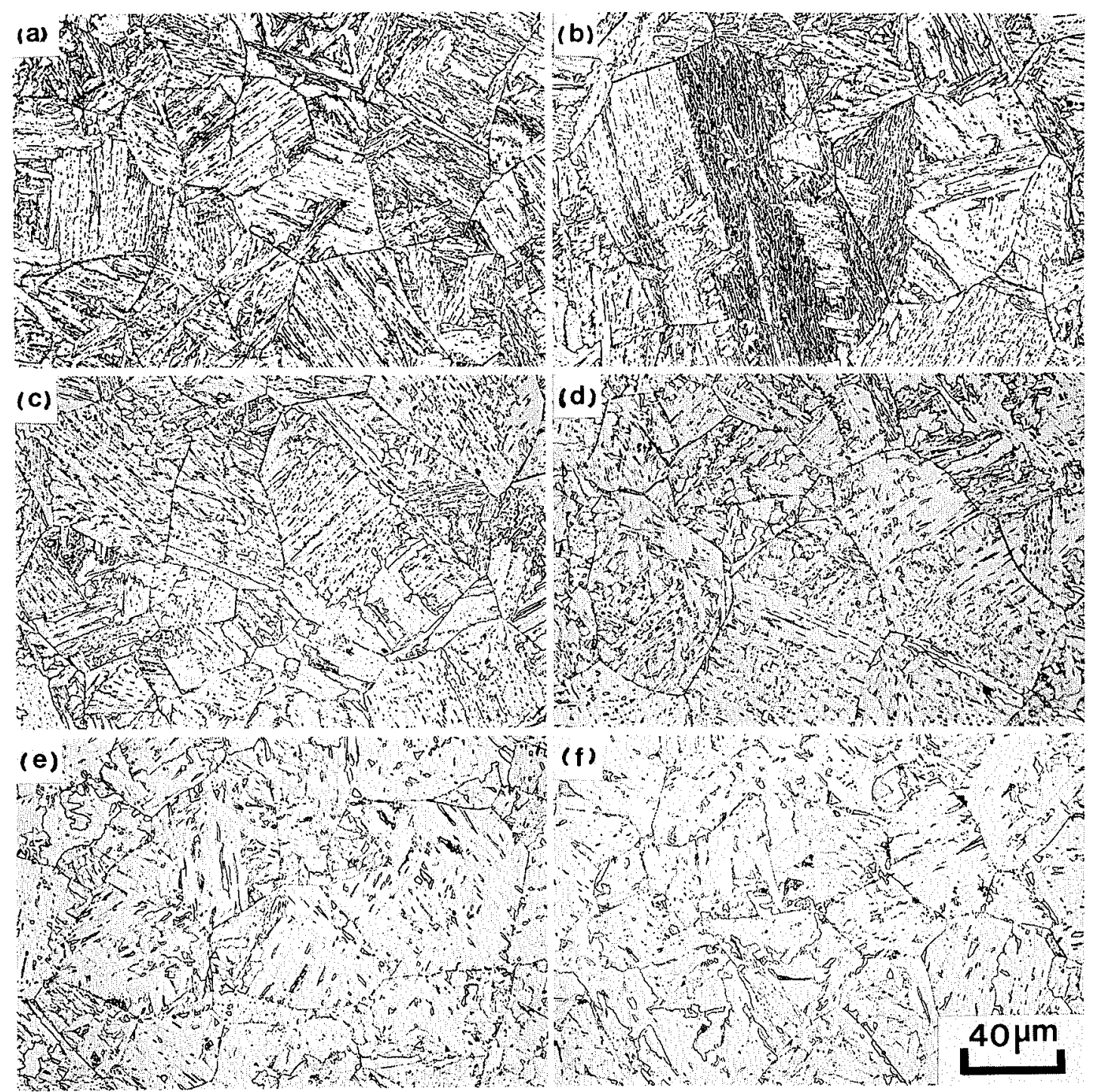

Fig. 3. Optical metallographs showing the development of the microstructure in Process $A$ at the variety of cooling rates: (a) 30 , (b) 20 , (c) 10 , (d) 5 , (e) 1 and (f) $0.5^{\circ} \mathrm{C} / \mathrm{s}$.

M/A constituent (light islands) and a few amounts of pearlite (dark islands). When the cooling rate decreases to $0.5^{\circ} \mathrm{C} / \mathrm{s}$ (Fig. 3(f)), parts of the prior austenite grain boundaries become unclear since they are decorated by allotriomorphic ferrite. The microstructure is composed mainly of bainitic ferrite matrix with a few amounts of allotriomorphic ferrite, some amounts of M/A constituent and a significant amounts of pearlite. On the other hand, Fig. 4 presents the optical microstructures obtained from the specimens treated in Process B at the same cooling rates as those using in Process A. The optical metallographs in Figs. 4(a), 4(b) and 4(c) display a high volume fraction of intragranularly nucleated acicular ferrite which is characterized by fine non-parallel ferrite platelets. As the cooling rate decreases to $5^{\circ} \mathrm{C} / \mathrm{s}$, the microstructure (Fig. 4(d)) tends to become sheaf-like bainite. The microstructure obtained from deformed specimens finally cooled at rates of 1 and $0.5^{\circ} \mathrm{C} / \mathrm{s}$ (Figs. 4(e) and 4(f)) are similar to those obtained from undeformed specimens cooled at the same rates (Figs. 3(e) and 3(f)). The results indicate that the intragranular nucleation of acicular ferrite is promoted in the deformed austenite only when the final cooling rates are higher. It is also noticed that the growth of acicular ferrite is impeded by austenite grain boundaries, which is analogous to the growth of bainite.

The scanning electron micrographs in Figs. 5(a) and 5(b) outline the morphologies of bainite and acicular ferrite for the cooresponding optical metallographs shown in Figs. 3(c) and 4(c). The M/A constituents can be found among the non-parallel plates of acicular ferrite, and appear as fine dispersions of islands (Fig. 5(b)). Whereas, thin layer like M/A constituents are aligned between the parallel plates of bainite (Fig. 5(a)). The striking transmission electron micrographs (Figs. 6(a) and 6(b)) also distinctly confirm the morphological difference between bainite and acicular ferrite for the corresponding optical metallographs showing in Figs. 3(c) and 4(c).

Although acicular ferrite which nucleates heterogeneously on the inclusion is common in the alloy-steel welds, acicular ferrite which forms on deformed austenite structure has not been reported widely in the alloy-steel plates. $^{6,7)}$ An investigation of orientation relationships 

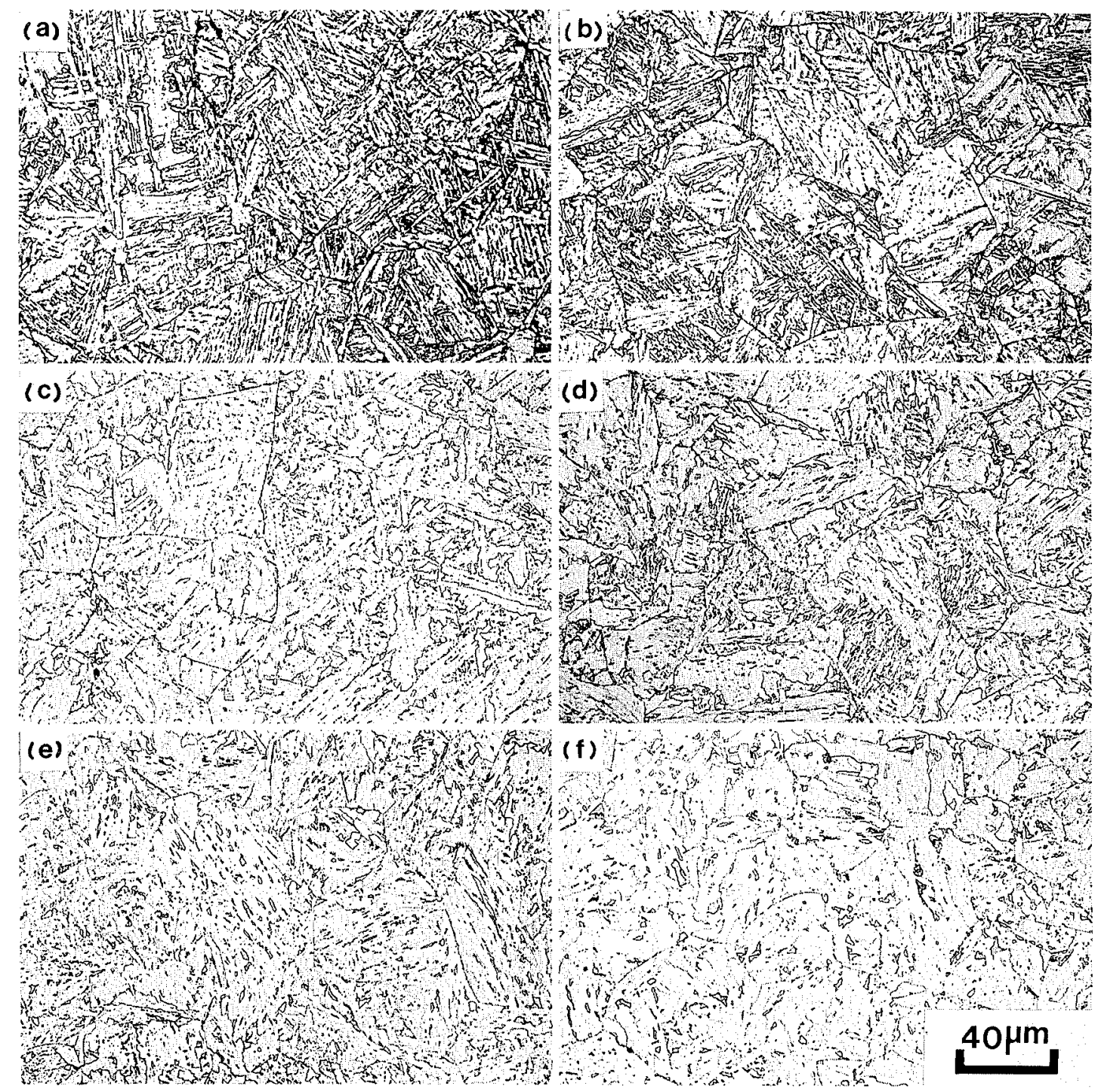

Fig. 4. Optical metallographs showing the development of the microstructure in Process $B$ at the variety of cooling rates: (a) 30 , (b) 20 , (c) 10 , (d) 5 , (e) 1 and (f) $0.5^{\circ} \mathrm{C} / \mathrm{s}$.

between adjacent grains of acicular ferrite (e.g. grains $\mathrm{A}$ and B shown in Fig. 6(b)) is reported for the present work. The orientation relationship between a pair of crystals with identical structure, the crystallographic bases of which are defined from a common origin, can be described using an axis-angle pair. From this it can be inferred that if one of the crystal is rigidly rotated about the specified axis which passes through the origin, through a right-handed angle of rotation $\theta$, its orientation coincides with that of the other. The results from several experiments are listed in Table 2, where axis-angle pairs relating adjacent variants of acicular ferrite are presented with the greatest angle of rotation, out of the 24 possibilities for each pair of acicular ferrite grains. Judging from the data, it appears that the adjacent variants have nearly the same orientation in space, which is similar to the case in alloy-steel welds. ${ }^{8}$ It should be noted that bainite grows in the form of sheaves, as clusters of parallel plates in very nearly the same crystallographic orientation.
A lot of investigations have shown that bainitic ferrite plates grow by a diffusionless and displacive transformation mechanisms, but immediately afterwards, the excess carbon is partitioned into the residual austenite. $^{9-15)}$ The transformation exhibits the phenomenon of incomplete reaction, in which the reaction ceases well before the residual austenite achieves its equilibrium carbon concentration. The reaction stops when the carbon concentration of the residual austenite reaches the $T_{0}^{\prime}$ curve on the phase diagram. ${ }^{9-15)}$ The $T_{0}^{\prime}$ curve* $^{*}$ delineates temperatures at which austenite and ferrite (with a certain amount of stored energy associated with transformation strains) of the same composition have equal free energy. The stored energy of bainitic ferrite have been determined to be $400 \mathrm{~J} / \mathrm{mol}^{.9,10)}$ Thus this diffusionless transformation is possible only if the carbon concentration of the residual austenite is less than the carbon concentration specified by the $T_{0}^{\prime}$ curve for the isothermal transformation temperature concerned. The schematic diagram shown in Fig. 7 presents the con-

\footnotetext{
* The corresponding curve for stress-free ferrite and austenite of identical composition is conventionally called the $T_{0}$ curve.
} 

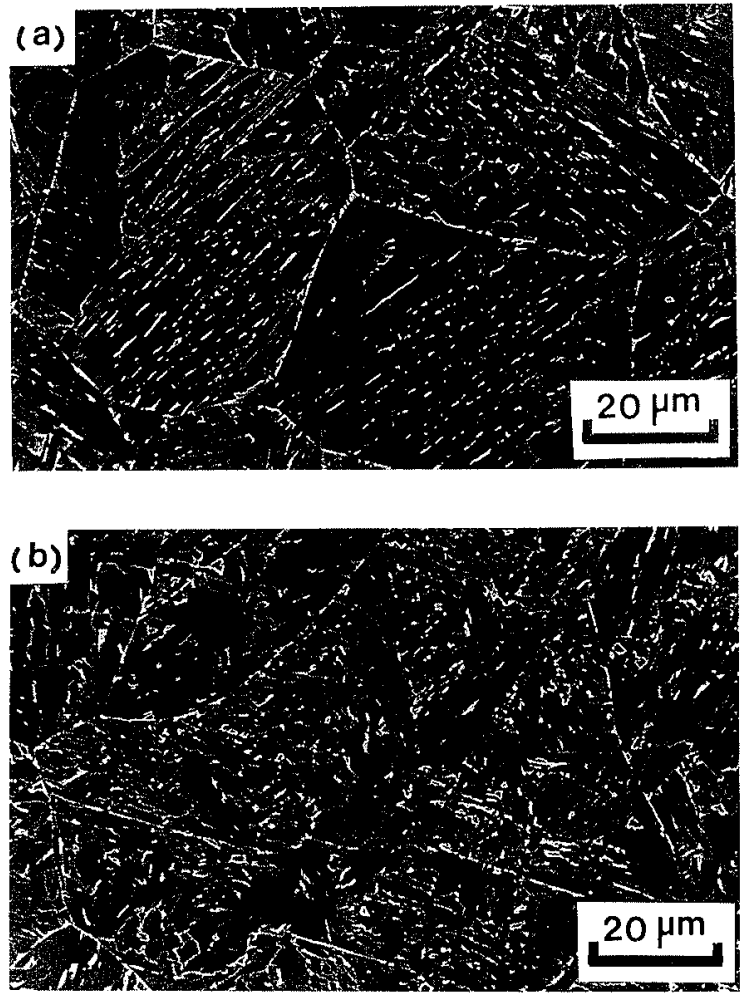

Fig. 5. Scanning electron micrographs (a) and (b) showing the microstructures for the corresponding optical metallographs of Figs. 3(a) and 4(c) respectively.
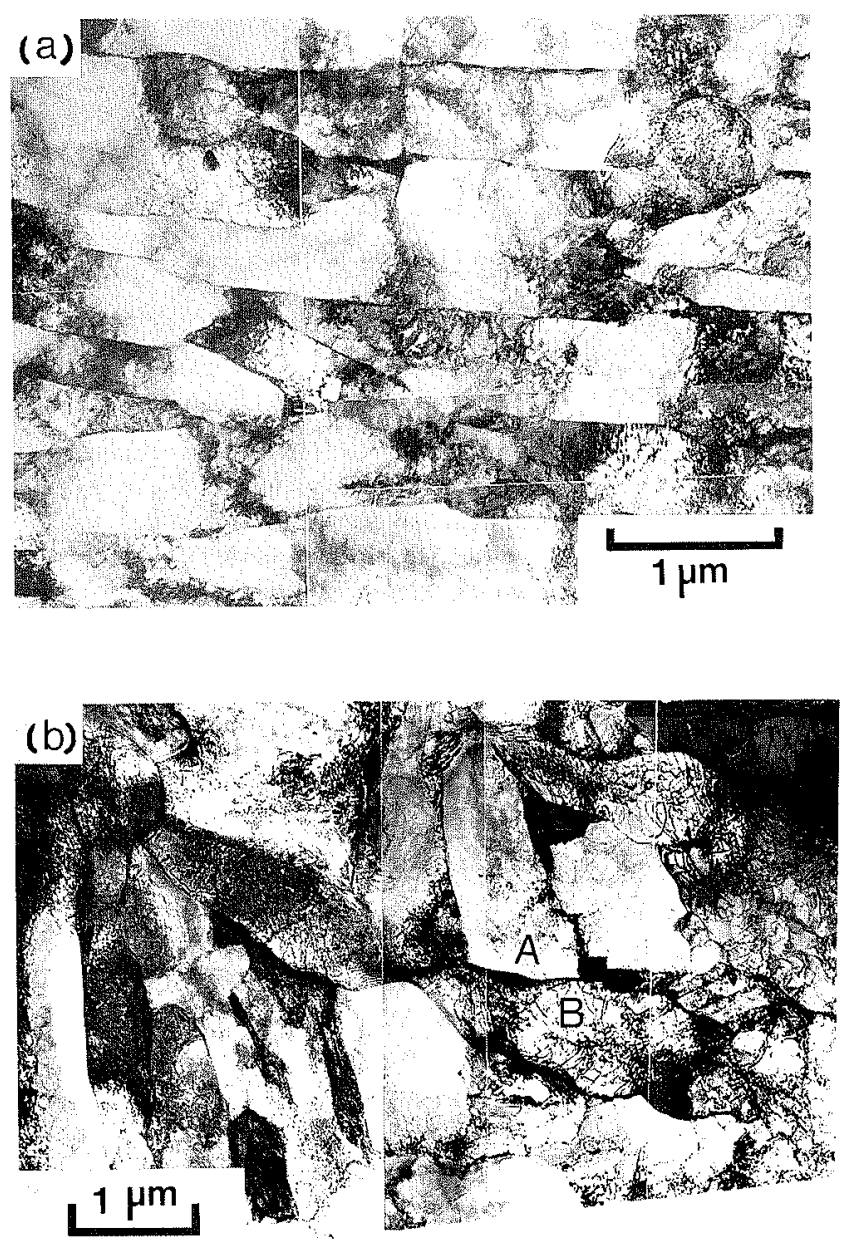

Fig. 6. Transmission electron micrographs (a) and (b) showing the microstructures for corresponding optical metallographs of Figs. 3(c) and 4(c) respectively.
Table 2. Orientation relationships between adjacent grains of acicular ferrite: axes are referred to crystallographic bases and rotation operations are right handed.

\begin{tabular}{rrrl}
\hline \multicolumn{3}{c}{ Axis } & Angle \\
\hline 0.7775 & 0.0410 & 0.6276 & 179.9 \\
-0.1300 & -0.5683 & -0.8125 & 176.7 \\
0.1606 & 0.6706 & 0.7242 & 180 \\
0.6100 & 0.7874 & 0.0887 & 176.6 \\
0.6209 & 0.7697 & 0.1488 & 180 \\
\hline
\end{tabular}

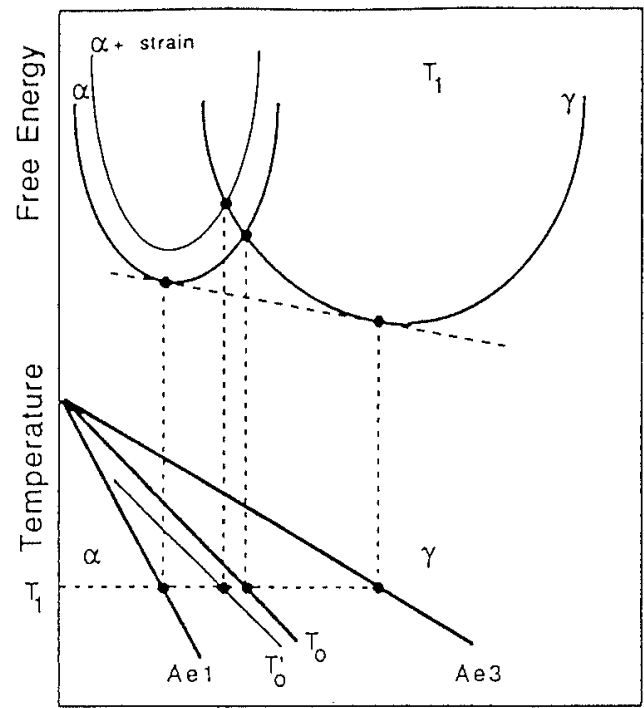

Carbon Concentration

Fig. 7. Schematic diagram showing the construction of phase boundaries from free-energy data. The $T_{0}^{\prime}$ line includes the effect of $400 \mathrm{~J} / \mathrm{mol}$ of strain energy due to bainite transformation.

struction of the $T_{0}^{\prime}$ curve from free-energy data. ${ }^{11)}$

For the purpose of exploring the transformation mechanism of acicular ferrite (formed from deformed austenite), and comparing with the transformation mechanism of bainite (formed from undeformed austenite), the data for thermodynamic analysis have been obtained from the specimens treated in Processes C and D. Figures 8 and 9 illustrate the scanning electron micrographs of bainite (with M/A constituents) and acicular ferrite (with M/A constituents) obtained from Processes $\mathrm{C}$ and $\mathrm{D}$ respectively after the isothermal transformations were complete. The corresponding residual austenite was transformed to M/A constituent during rapid cooling to room temperature. Hence, the volume fraction of residual austenite (after the isothermal reaction of bainite stops) can be estimated directly from the volume fraction of $\mathrm{M} / \mathrm{A}$ constituent. The volume fraction of the M/A constituent versus the isothermal temperature is ploted in Fig. 10. It shows that prior deformation of austenite slightly promotes the acicular ferrite transformation when compared with the other case, where the bainite forms from underformed austenite. The amount of M/A constituents formed with acicular ferrite is less than that formed with bainite. However, both cases show the similar trend that the amount of M/A constituent decreases with decreasing the isothrmal temperature. The 

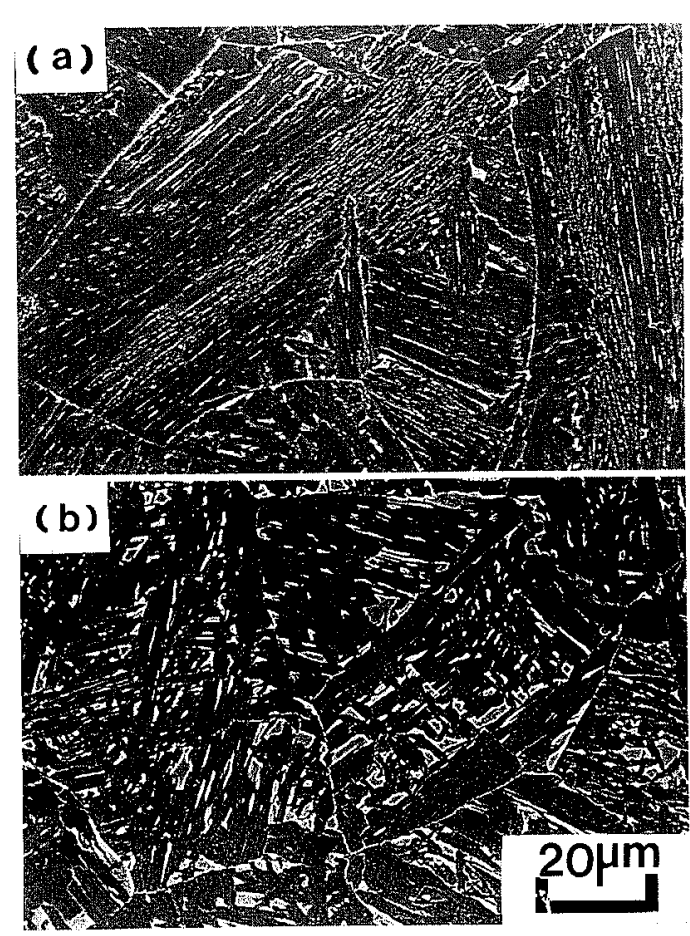

Fig. 8. Scanning electron micrographs illustrating the microstructures obtained in Process $\mathrm{C}$ after completing the isothermal transformation of bainite and rapidly to room temperature.

(a) Isothermal transformation at $525^{\circ} \mathrm{C}$ for $30 \mathrm{~min}$.

(b) Isothermal transformation at $575^{\circ} \mathrm{C}$ for $30 \mathrm{~min}$.
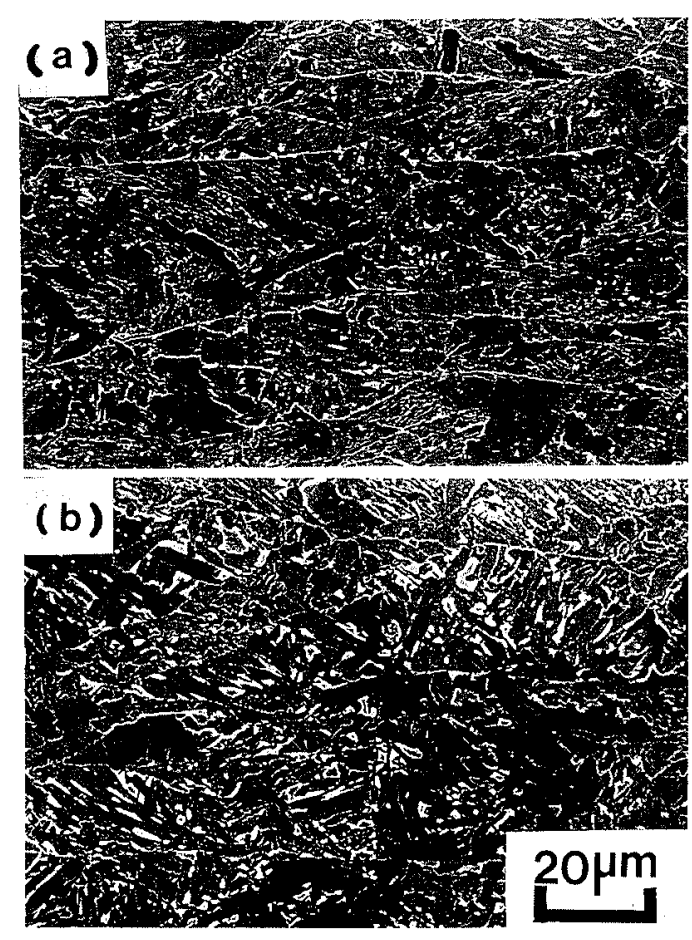

Fig. 9. Scanning electron micrographs illustrating the microstructures obtained in Process D after completing the isothermal transformation of acicular ferrite and rapidly cooling to room temperature. The observed section was parallel to the longitudinal direction of the dilatometric specimen.

(a) Isothermal transformation at $525^{\circ} \mathrm{C}$ for $30 \mathrm{~min}$

(b) Isothermal transformation at $575^{\circ} \mathrm{C}$ for $30 \mathrm{~min}$.

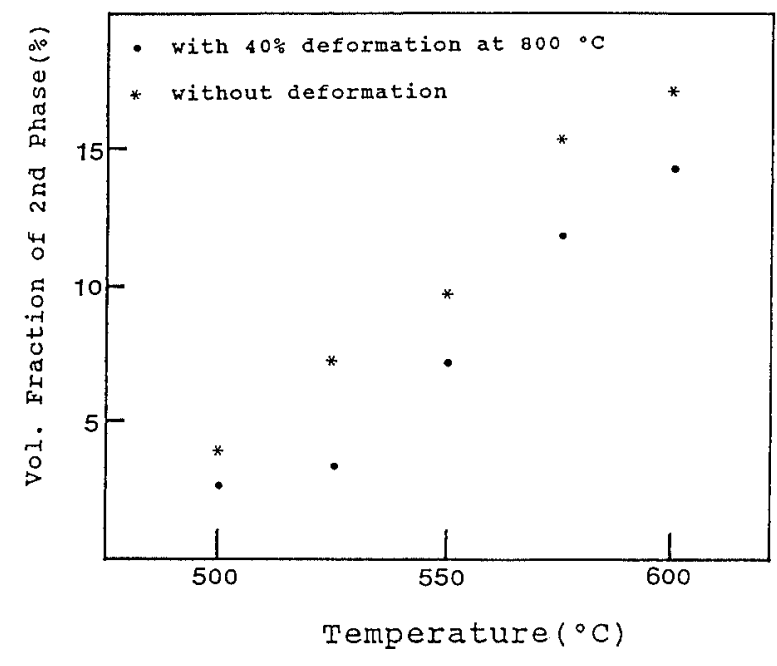

Fig. 10. Plot of the volume fraction of $\mathrm{M} / \mathrm{A}$ constituent versus the isothermal temperature.

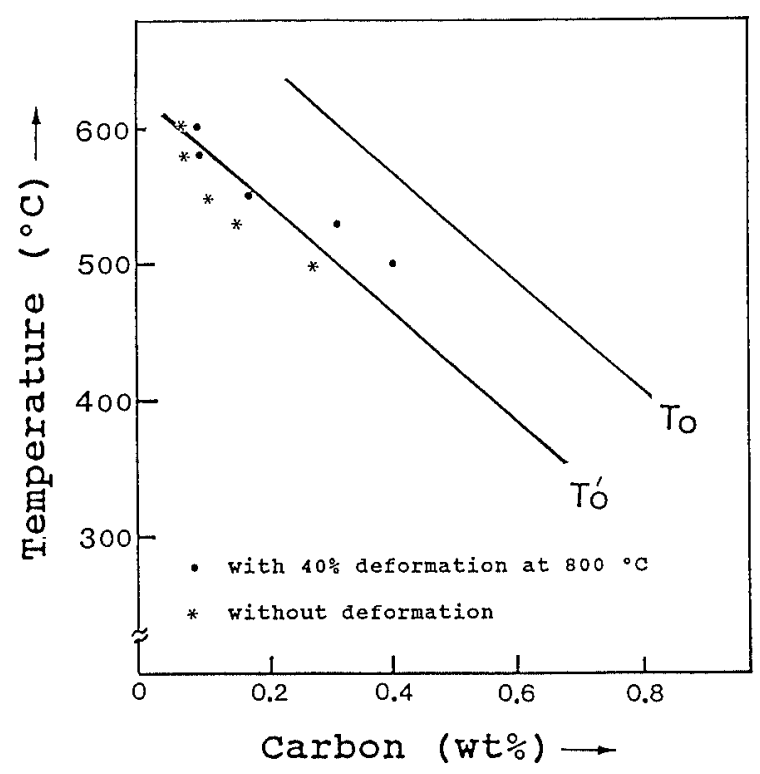

Fig. 11. Calculated $T_{0}$ and $T_{0}^{\prime}$ curves for the steel studied. The calculations are carried out using the method detailed in Ref. 16). The experimental data indicate the acicular ferrite transformation ceases as the carbon content of residual austenite reaches the appropriate value given by the $T_{0}^{\prime}$ boundary.

carbon content of the M/A constituent has been calculated, according to the mass balance equation of carbon:

$$
C=C_{m} V_{m}+C_{a} V_{a} \text { or } C=C_{m} V_{m}+C_{b} V_{b},
$$

where $C_{m}, C_{a}$ and $C_{b}$ are the carbon contents of M/A constituent, acicular ferrite and bainite respectively, and $V_{m}, V_{a}$ and $V_{b}$ are the volume fractions of $\mathrm{M} / \mathrm{A}$ constituent, acicular ferrite and bainite correspondingly. Both $C_{a}$ and $C_{b}$ are taken to be $0.02 \mathrm{wt} \%$. The calculated $C_{m}$ as a function of the isothermal transformation temperature is plotted in Fig. 11. The $T_{0}$ and $T_{0}^{\prime}$ curves in Fig. 11. were calculated for the steel studied, using the analysis of Bhadeshia and Edmonds. ${ }^{16)}$ It is obvious from Fig. 11 that the acicular ferrite transformation teminates well before the carbon content of residual 
austenite reaches the $T_{0}$ curve. If the stored energy $400 \mathrm{~J} / \mathrm{mol}$ is taken into account, then some of the data slightly exceed the $T_{0}^{\prime}$ curve. The experiment reported in Fig. 11 confirms the incomplete reaction phenomenon. ${ }^{13-16)}$ It implies that the transformation mechanisms of acicular ferrite and bainite are apparently similar, with the displactive characteristic. The results from thermodynamic analysis are consistent with those from metallographic observation (Figs. 3(a)-3(e)) and $4(\mathrm{a})-4(\mathrm{e}))$. The growth of displacive product involves a coordinated movement of the substitutional solute and iron atoms across transformation interface. Such coordinated movement cannot be substained across austenite grains which are randomly oriented. The growth of displacive product is impeded by austenite grain boundaries; this contrasts with diffusional transformations in which the product phase may readily grow across grains of the parent phase that are in different orientation. ${ }^{13}$ )

The state of austenite prior to transformation is of deciding importance as the austenite structure influences the nucleation sites for bainite and acicular ferrite. The volume fraction of bainite and acicular ferrite should depend on the relative amounts of austenite grain boundaries and intragranular nucleation sites available. In this work, the deformation temperature was much lower than the recrystallization temperature. When the deformed austenite is cooled at a variety of rates, the structure of austenite may exist in the various conditions ranging from heavily deformed to fully recovered states. At the higher cooling rate, the deformation structures (i.e., deformation bands) could be preserved until austenite decomposition occurred. In such a condition, the bainite transformation initiated at austenite grain boundaries was stifled and the morphology of sheaves could not be developed; whereas the nucleation at the intragranular heterogeneities (i.e., boundaries of deformation bands) was promoted and led to the morphology of non-parallel plates. As the final cooling rate decreased to $5^{\circ} \mathrm{C} / \mathrm{s}$, the morphology of sheaves became dominant. It is suggested that the cooling rate $5^{\circ} \mathrm{C} / \mathrm{s}$ should be substantially slow enough to bring about the recovery of the deformed austenite during continuous cooling and consequently the intergranular nucleation is not preferable.

\section{Conclusions}

The findings in the present work can be summarized as follows:

(1) From the thermodynamic analysis and metallo- graphic observation, it shows that the transformation mechanisms of acicular ferrite and bainite are apparently similar, with the displactive characteristic.

(2) The orientation relationships between adjacent grains of acicular ferrite in deformed samples have been determined. It can be seen that clusters of acicular ferrite grains form in such a way that adjacent grains tend to have a similar orientation in space. The result is similar to that for bainite sheaf structure, in which all the plates are in approximately the same crystallographic orientation.

(3) At the higher cooling rates $\left(30,20\right.$ and $\left.10^{\circ} \mathrm{C} / \mathrm{s}\right)$ the deformed austenite tends to form the intragranular non-parallel platelets of acicular ferrite; while at the lower cooling rates $\left(5,1\right.$ and $\left.0.5^{\circ} \mathrm{C} / \mathrm{s}\right)$ the deformed austenite tends to form sheaf-like parallel platelets of bainite. It is suggested that the intergranular nucleation in deformed austenite should not be preferable as the final cooling rate is substantially slow to bring about the recovery during continuous cooling.

\section{REFERENCES}

1) H. K. D. H. Bhadeshia: Steel Technology International, ed. by P. H. Scholes, Stering, London, (1989), 289.

2) H. Nakasugi, H. Matsuda and H. Tamehiro: Alloys for the 1980's, Climax Molybdenum, Ann Arbor, MI, (1980), 213.

3) H. Nakasugi, H. Matsda and H. Tamehiro: Steels for Line Pipe and Pipeline Fittings, Met. Soc. London, (1983), 90.

4) K. Hulka, F. Hesterkamp and L. Nachtel: Processing, Microstructure and Properties of HSLA Steels, TMS, Warrendale, PA, (1988), 153.

5) C. Y. Huang, J. R. Yang and S. C. Wang: Mater. Trans. JIM, 8 (1993), 658

6) J. R. Yang and H. K. D. H. Bhadeshia: J. Mater. Sci., 26 (1991), 839.

7) T. Araki, M. Enomoto and K. Shibata: Mater. Trans., JIM, 32 (1988), 113.

8) J. R. Yang and H. K. D. H. Bhadeshia: Mater. Sci. Technol., 5 (1989), 93.

9) H. K. D. H. Bhadeshia: Acta Metall., 29 (1981), 1117.

10) H. K. D. H. Bhadeshia and A. R. Waugh: Acta Metall., 30 (1982), 775 .

11) J. R. Yang and H. K. D. H. Bhadeshia: Advances in Welding Science and Technology, Conf. Proc., ASM, Materials Park, Ohio, (1987), 187.

12) M. Strangweed and H. K. D. H. Bhadeshia: Advances in Welding Science and Technology, Conf. Proc., ASM, Materials Park, Ohio, (1987), 209.

13) H. K. D. H. Bhadeshia and J. W. Christian: Metall. Trans. A, 21 (1990), 209.

14) J. R. Yang and H. K. D. H. Bhadeshia: Mater. Sci. Eng. A, 131 (1991), 99.

15) A. Ali, M. Ahmed, F. H. Hashmi and A. Q. Khan: Metall. Trans. A, 24 (1993), 2145.

16) H. K. D. H. Bhadeshia and D. V. Edmonds: Acta Metall., 28 (1980), 1265 . 